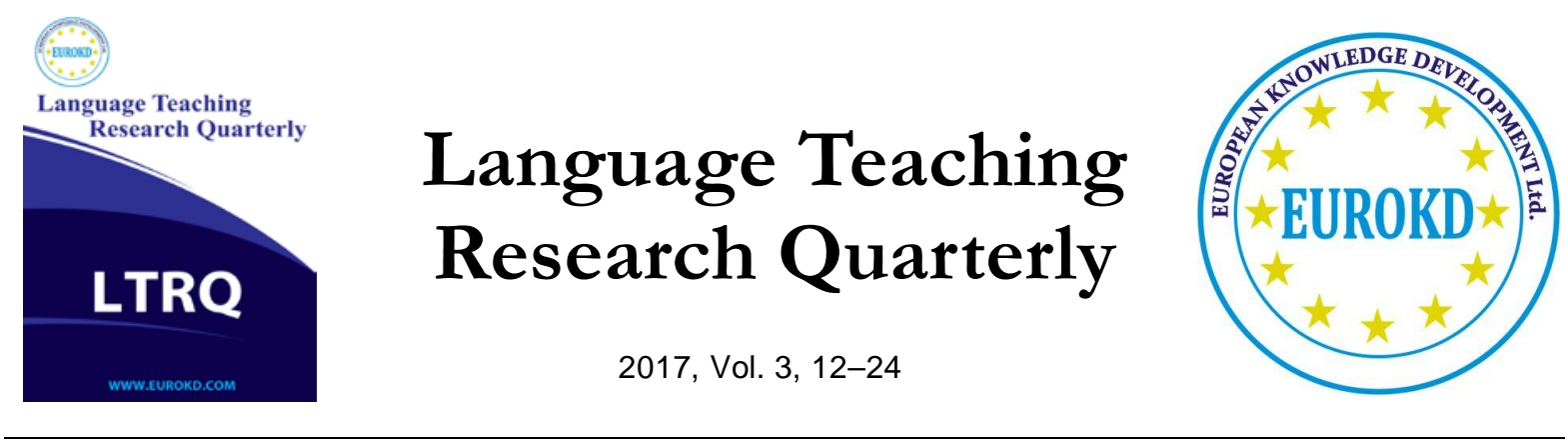

\title{
Acquisition of Future Perfect Progressive Tense by Persian L2 Learners of English: The Interpretability Hypothesis
}

\author{
Zahra Sadri ${ }^{1, *}$, Hamide Behroueian ${ }^{1}$, Anahita Khosravi² \\ ${ }^{1}$ M.A. in TEFL, Yazd University, Yazd, Iran \\ ${ }^{2} \mathrm{M}$.A in TEFL, Department of English, Bandar Abbas Branch, Islamic Azad University, Bandar Abbas, \\ Iran
}

Received 3 May 2017 Accepted 19 August 2017

\begin{abstract}
The issue of non-native speakers' divergence from L2 input has gained popularity in the field of second language acquisition during the previous decades. Many significant scholars have joined the discussion and tried to explain this phenomenon through various models and frameworks. In this regard, the present study discussed domains of divergence within the framework of interpretability hypothesis. To this end, syntactic structures of future perfect progressive tense were compared in English and Persian. To examine the validity of Interpretability Hypothesis (IH), 30 Iranian L2 learners at intermediate and advanced levels were selected based on the oxford quick placement test. Further, learners were required to answer two translation tests containing English to Persian (comprehension test) and Persian to English (production test) sentences. Results revealed that learners had no problem in comprehension of this tense; however, when it came to production, they experienced some instances of divergence. Based on the findings, underpinnings of IH are supported in the sense that the logically interpretable English future perfect progressive tense poses little problem for learners whose L1 lacks the tense phonologically. Moreover, the results showed that Persian learners resort to some other compensatory tenses to express futurity in their L1.
\end{abstract}

Keywords: Future Perfect Progressive Tense, Interpretability Hypothesis, Oxford Quick Placement Test, Second Language Acquisition

\section{Introduction}


Universal grammar (UG) in linguistics, was proposed for the first time by Noam Chomsky. The proponents of this theory emphasize and partially focus on the existence of some universal properties of natural human languages and the poverty of the stimulus (POS) argument asserting that natural language grammar is underdetermined, or impossible to sustain itself due to relatively limited data available to language acquirer. The corstone of the Principles and Parameters theory is that children acquire the L1 by resorting to UG that consists of a set of principles and a set of parameters. The principles are universal that is they are true for all human languages; however, the parameters differ, within certain limits, from one language to another. According to this theory, when children are exposed to an L1, they can form phrases from early age because they have access to a language faculty which involves the principles that enable them to do so. On the contrary, children adjust the specific features; that is the language parameters based on the language input they receive from the environment. For instance, there is an idea asserting that the movement in sentences does not depend on the sequence of words but on the structural dependency of them; that is known as "Structure Dependency Principle" and exists in all languages (Cook, 1985). On the other hand, the pro-drop parameter is an example of a parameter in UG. Some languages such as Arabic and Persian are allowed to have null subject in declarative sentences, while others, such as English, are not.

\section{UG and First Language Acquisition}

There are some phenomena which support the role of UG in L1 acquisition, including underdetirmination, systematicity and the evidence.

Firstly, underdetermination is the fact that L1 acquirers are able to produce sentences that they have never heard before and they can easily judge the grammaticality of sentences. For instance, they know that Is John who is a teacher good? is grammatical; whereas, *Is John who a teacher is good? is not grammatical. White (1989) points out that the language faculty, which contains UG, facilitates L1 acquisition.

Secondly, systematicity suggests that children acquire language under systematic processes. For example, when English children acquire negation they proceed the same stages. In early stages, they use 'no' before verbs and after auxiliaries such as '*he no drink coffee' and '*he is no happy'. Next, they learn how to use the auxiliary ' $d o$ ' with 'not', but they do not differentiate between the use of 'does', which is used with the third person singular pronouns, and 'do', which is used with other pronouns. They always use ' $d o$ '. Hence, they say things like '*he don't drink coffee' and 'we don't drink coffee'. Last, they acquire the correct form of negation in English (Cook, 1993).

Thirdly, the child needs to be exposed to a particular language in order to acquire a language. This exposition leads him or her to the evidence that contributes them to correctly construct the structures in their languages. This evidence can be positive or negative. The actual sentences that the child encounters are called positive evidence is. For example, the child of English by hearing the order of Subject-Verb-Object knows that English has such an order. By contrast, negative evidence has two types; namely, direct and indirect. Direct evidence pertains to 
correction of mistakes that a child does in during acquiring L1. On the other hand, if some grammatical structures do not appear in a language, they do not belong to that language according to indirect evidence. For instance, if a child does not hear the Subject-Object-Verb order in English, so he or she knows that English does not have such an order (Cook, 1985). Accordingly, positive evidence and, to some extent, indirect evidence lead to L1s acquiring; whereas, direct evidence or correction have no role in L1 acquisition.

Various scholars posed different hypotheses about availability of universal grammar in second language acquisition process. In the following, different models proposed in this field are presented.

\section{UG and Second Language Acquisition}

UG includes principles and parameters that constraint grammars in the course of L1 acquisition and also grammars in the process of adult native-speaker. L2 learners also need to achieve a linguistic system which accounts for the L2 input, allowing the learner to understand and speak the second language. Therefore, both L2 learners and L1 acquirers face a similar task in the process of achieving a comprehensive linguistic system. Considering this clear similarity, the question of whether UG also mediates L2 acquisition, and to what extent, has been explored and debated since the early 1980s. The first wave of research targeted toward the availability of UG in non-primary acquisition or so-called access issue. There are four models which represent the role of UG in SLA.

\section{The direct access model}

The advocates of this position believe that UG is directly available and L2 learners have access to it separately from the L1 (Otsu and Naoi, 1986; Ritchie, 1978). Otsu and Naoi examined Japanese L1 learners of English L2. They investigated the operation of the Subject-Dependency Principle in the L2. While English allows the movement of the auxiliary 'is' in sentence, Japanese does not. Moreover, yes-no questions are formed in Japanese by adding a question particle to the sentences without changing the order of the words. The participants had been asked to transform 12 declarative sentences containing relative clauses into questions. They found that most of the participants resorted to UG and produced the interrogatives correctly. According to their results, they concluded that L2 learners have direct access to UG. Some of those who deny the direct availability of UG in the process L2 acquisition reject Otsu's and Naoi claim since their subjects were too young, hold that it is clear that young children have full access to UG, and restrict UG availability to adult L2 learners. One of the other supporters of this model is Ritchie (1978) who tested the operation of the Right Roof Constraint (RRC) using a grammaticality judgment test. He concluded that the RRC is operating and UG is accessible to L2 learners. However, his study was rejected by some researchers since most of his subjects also had been taught English at school on Japan from the age of 13 and they were not really adult. These two aforementioned studies seem to confirm the availability of UG in L2 acquisition by supporting Underdetermination Principle, as an evidence of the role of UG in L1 
acquisition. Moreover, Otsu and Naoi and Ritchie’s studies showed that subjects have the ability to produce sentences that they do not have in their L1 and did not learn in the L2.

The indirect access model

According to this model, UG operates in L2 acquisition, but through the L1 (White, 1986; and Flynn, 1987), that is L2 learners start learning the second language while he/she is equipped with principles and parameters of L1 and where the parametric value differs from the L2, he/she resets the parameters of the L1. In other words, L2 learning operates on the base of L2 input and with activity of UG. White (1986) compared French learners with Spanish learners of English (French and English are non-pro-drop languages, while Spanish is pro-drop language) using a grammaticality judgment test. observing that Spanish learners produced sentences with null subject much more than French learners at first stages, she assumed that Spanish learners had been impressed by their L1 parameters particularly at first stages. White (1989) summed up this model by introducing two different hypotheses induced from the indirect access model:

1. UG is inaccessible but any aspects of it that is available in the process of L1 acquisition can be used in the L2 learning.

2. L2 learners initially speculate the L1 parameters, but are still able to tap UG. Therefore, they can reset the L2 parameters.

\section{The no-access model}

UG is not available to L2 learners according to this model and the parameters setting in the L1 cannot be resettles for L2 acquisition. Proponents this model, assume that there are major differences between L1 and L2 acquisition (Clahsen and Muysken, 1986). Schachter (1988, 1989) examined the accessibility of UG during L2 acquisition using grammaticality judgment test; and concluded that UG is unavailable to L2 learners, since they do not use the principle for structures that they know already. Schachter holds that merely the activated principles in the L1 are accessible in an L2. Bley-Vorman (1989) has attributed any inefficiency in L2 learning to unavailability of UG for L2 learners and holds that L2 learners acquire L2 using other mental processes such as general learning strategies.

\section{The overall model}

Felix (1985) calls this model 'the competition model'. Ellis (1994), also, names it 'the dual model' meaning that L2 learners have partial access to UG. These two researchers correspond the language specific system to UG, and believe that the problem solving system enter into competition for acquisition in light of L2 input. According to this model, only children achieve full competence since they have complete access to UG; whereas, adults access to UG is partially blocked by using the problem solving system accounting for the fact that adults do not success in having native-like competence. In agreement to Felix and Ellis's model, Towell and Hawkins (1994) have proposed 'the overall model'. Based on Felix and Ellis, monolingual learners usually assume that other languages are similar to their L1s and they are more likely to 
use their L1 parameter setting to the L2. Encounter L2 input, they may even make rules to mimic the surface properties of the L2, while preserving the L1 parameter setting. However, it is worth to mention that such mimicking is limited by the possibilities allowed by UG. Moreover, during first stages, they derive L2 forms using the L1. To do this, learners face two possibilities: they may transfer a parameter setting, or they may mimic by resorting to from UG. Internally derived hypotheses are made by learners by combining these two possibilities.

One of these recent hypotheses pertaining to partial access to UG is Interpretability Hypothesis introduced by some researchers (Hawkins and Hattori, 2006; Tsimpli and Dimitrakopoulou, 2007; Tsimpli and Mastropavlou, 2007). According to this hypothesis, uninterpretable syntactic features are unavailable for second language learners after a critical period; however, interpretable features are available for them lifelong. This hypothesis is supported by some researchers (Kong 2005; Hawkins and Hattori, 2006; Al-Thubaiti, 2007; Tsimpli and Mastropavlou, 2007) and rejected by some others (Montrul, Foote et al. 2006; Tanner, 2008, Rothman, Iverson et al. 2009; Rothman, Judy et al. 2010; Bond, Gabriele et al. 2011).

\section{Statement of the problem}

This paper investigated the role of L1 in acquisition of L2 future perfect progressive tense in terms of logical and phonological interpretability. In recent years a great number of studies have been dedicated to differential difficulty in acquisition of language modules, interfaces, operations, and constructions (Prévost and White, 2000; Domínguez and Arche, 2008; Hodgson, 2009). However, partial availability of UG was argued even at the advanced levels of language development which explains resistance of parameter resetting (Tsimpli and Dimitrakopoulou, 2007). In this study, assumptions proposed by two hypotheses in generative literature were tested, i.e., interpretability hypothesis and interface hypothesis. The interface hypothesis concentrates on two levels of grammar-meaning interface; interpretable and uninterpretable levels. Interpretable features result in semantic interpretation; hence, their elimination isn't possible. Uninterpretable features, on the other hand, are possible to be deleted from the sentence since they are restricted to syntactic operations and fail to contribute to semantic meaning. The interpretability hypothesis (IH) assumes accessibility of UG principles and lack of parameter resetting if a syntactic feature is logically uninterpretable. In accordance with this hypothesis, logically interpretable features cause fewer problems for learners while uninterpretable ones are found quite problematic. In fact, this hypothesis articulates the effects of critical period constraints and maturity on resistance of parameter resetting and the way such factors lead to uninterpretability. In order to accentuate the main principles of IH, an LFinterpretable but PF-uninterpretable tense in Persian was compared to its English equivalent. Future perfect progressive tense which is both logically and phonologically interpretable is used to emphasize that an action has been taken place up to the time of another action in the future.

Futurity in English and Persian 
A number of linguists express doubt regarding the existence and structure of future tense in English. For example, Quirk and Greenbaum stated that future tense has no obvious pattern in English as opposed to present and past; however, there are several possibilities to denote the idea of futurity. They further declared that future tense can be presented through modals, auxiliaries, semi-auxiliaries, or by simple present and present progressive forms (Quirk and Greenbaum, 1973).

From among several available options for rendering futurity in English, the focus of this paper was on future perfect progressive tense (FPPT) which is constructed as: will/shall + have + been + verb + ing.

Simple future in English can be classified into two categories of predictive future and impositional future. Simple future (will + base verb) is classified as a predictive future since it lacks any additional present information. In Persian, simple future tense is constructed by conjugating the present stem /xah/ of the auxiliary /xastan/ + present inflectional endings and adding the outcome to the short -infinitive of the base verb.

(1a) I will study tonight.

(1b) man emšab motâle e xâham kard.

The future formal pattern of xah + present inflectional endings + short infinitive is statistically the most frequent future tense in Persian. In a nutshell, the formal pattern of future in Persian corresponds exactly to the simple predictive future in English. Since the semantic schemata of two languages are based on the basic meaning of forms available in each language discourse. Acquiring English simple future tense may bring the least learning problems to the native speakers of Persian (Fallahi, 1991). However, when it comes to FPPT, two languages are quite different. According to Yarmohammadi, FPPT is classified as an impositional future (Yarmohammadi, 2005). This category includes a particular attitudinal orientation in addition to a future marker. Persian language lacks these modally-colored attitudes; therefore, it causes learning problems for Persian learners. In other words, Persian lacks a formal and stable pattern that could be called a FPPT (Yarmohammadi, 2005). It is assumed that in English FPPT is logically and phonologically interpretable; however, in Persian, this tense is phonologically unintepretable. Persian speakers wrongly resort to other tenses namely simple future (Fallahi, 1991), present perfect (Mirhassani, 1989), and future progressive to denote FPPT in translating from L2 to L1.

(2a) By the time you arrive tonight, I will have been studying for two hours.

(2b) ta vaqti shoma emshab berasi dou saat motale-e kard-e am.

(2c) ta vaqti shoma emshab berasi dou saat motale-e xaham kard.

\section{Method}

Hypotheses

In this paper, three hypotheses were considered: 
1. Based on interpretability hypothesis, Persian L2 learners of English will have no learning problems in comprehension and production of FPP sentences.

2. Based on interface hypothesis, Persian L2 learners will eliminate uninterpretable features while producing or translating FPP English sentences to Persian.

3. The two most frequent tenses which are used as compensatory tenses for rendering FPPT in Persian are simple future and present perfect.

\section{Participants}

A total number of 30 participants were selected from 85 non-native English speaking Iranian students studying in a private language institute in Yazd. Students took the Oxford Quick Placement Test (OQPT) and were classified into two levels of advanced $(n=16)$ and intermediate $(\mathrm{n}=14)$ proficiency levels based on their scores (a score within 50-60 for advanced and 40-50 for intermediate proficiency level).

To collect data, two tests, i.e., comprehension and production tests were developed. Participants were further divided into two groups; each group took one test. Group one who took the comprehension test comprised of 6 intermediate and 9 advanced students. The second group who took the production test consisted of 8 intermediate and 7 advance students.

The comprehension test included 15 Future Perfect Progressive (FPP) English sentences and participants were asked to choose the best Persian equivalent from the options provided according to Yarmohammadi (2005) and suggestions made by some proficient Persian literature teachers. Moreover, participants were allowed to choose two options regarding this test.

In the production test, participants were required to choose the best English equivalent for the provided 12 Persian sentences. Options of this test were designed based on participants' answers to the first test. The difference between the two groups lied in the fact that members of group one were provided with some hints about FPP tense. During the test, there was no time limit and participants had enough time to consider all the options.

\section{Materials and Procedure}

Comprehension test

Participants in group one were given a test including 15 English FPP sentences. At the top of the test paper a brief explanation of FPP as well as some instructions about possibility of choosing two options were provided for participants. The options were simple future (Fallahi, 1991), present perfect (Mirhassani, 1989), and simple present (suggested by some proficient literature teachers). There was no time limit and participant had enough time to consider all the options. The distribution of answers is shown in Table 1. 
Table 1: Distribution of answers to comprehension test

\begin{tabular}{lllll}
\hline & g1etop & Mean & Std. Deviation & $\mathrm{N}$ \\
\hline \multirow{3}{*}{ sf1 } & Intermediate & 2.17 & 3.488 & 6 \\
& Advanced & .67 & 1.323 & 9 \\
& Total & 1.27 & 2.434 & 15 \\
\hline \multirow{3}{*}{ pp1 } & Intermediate & 5.33 & 5.317 & 6 \\
& Advanced & 4.44 & 3.539 & 9 \\
& Total & 4.80 & 4.178 & 15 \\
\hline \multirow{3}{*}{ sp1 } & Intermediate & 1.17 & 1.472 & 6 \\
& Advanced & 3.00 & 3.391 & 9 \\
& Total & 2.27 & 2.865 & 15 \\
\hline \multirow{3}{*}{ pp\&sp1 } & Intermediate & 6.17 & 5.037 & 6 \\
& Advanced & 6.89 & 6.698 & 9 \\
\hline Sp $=$ simple present & Sf $=$ simple future & \multicolumn{2}{c}{ Pp = present perfect }
\end{tabular}

One item from the comprehension test is provided in the following. The entire form of test is provided in Appendix A.

(1) They will have been talking on phone for over an hour by 6 o'clock.

a- Tâ sâat 6 bištar az yek sâat ast ke anha sohbat karda-and.

b- Tâ sâat 6 bištar az yek sâat ast ke anha sohbat mikonand.

c- Tâ sâat 6 bištar az yek sâat ast ke anha sohbat xâhand kard

\section{Production test}

Participants in group were required to answer the production test including 12 Persian sentences that denoted FPPT. They should choose the best English equivalent for each Persian sentence from the provided options. The options were extracted from Fallahi (1991) and included simple future, present perfect, future progressive, and future perfect progressive. The distribution of answers regarding this test is represented in Table 2.

An example of production test is provided in the following. The entire form of production test is provided in Appendix B.

(2) Tâ bâznešast šavi âya 20 sâl ast ke dar landan zendegi mikonid/ karda-id?

a - When you retired, will you live in London for 20 years?

b - When you retired, have you lived in London for 20 years?

c - When you retired, will you be liv in London for 20 years?

d - When you retired, will you have been living in London for 20 years? 
Table 2: Distribution of answers to production test

\begin{tabular}{|c|c|c|c|c|}
\hline & g2ptoe & Mean & Std. Deviation & $\mathrm{N}$ \\
\hline \multirow{3}{*}{ sf2 } & Intermediate & .25 & .463 & 8 \\
\hline & Advanced & .43 & .535 & 7 \\
\hline & Total & .33 & .488 & 15 \\
\hline \multirow{3}{*}{ pp2 } & Intermediate & 5.62 & 3.701 & 8 \\
\hline & Advanced & 3.71 & 2.059 & 7 \\
\hline & Total & 4.73 & 3.105 & 15 \\
\hline \multirow{3}{*}{ fp2 } & Intermediate & 1.00 & 1.069 & 8 \\
\hline & Advanced & 3.57 & 3.259 & 7 \\
\hline & Total & 2.20 & 2.624 & 15 \\
\hline \multirow{3}{*}{ fpp2 } & Intermediate & 5.12 & 3.227 & 8 \\
\hline & Advanced & 4.14 & 3.388 & 7 \\
\hline & Total & 4.67 & 3.222 & 15 \\
\hline
\end{tabular}

\section{Results}

In this section the results obtained from forced choice elicitation tasks are analyzed and revealed.

\section{Comprehension test}

As it can be seen in Figure 1, majority of learners chose present perfect and simple present as the best equivalent tenses for rendering an action that has been taking place up to the time of another action in the future.

Figure 1: Distribution of answers regarding tenses 


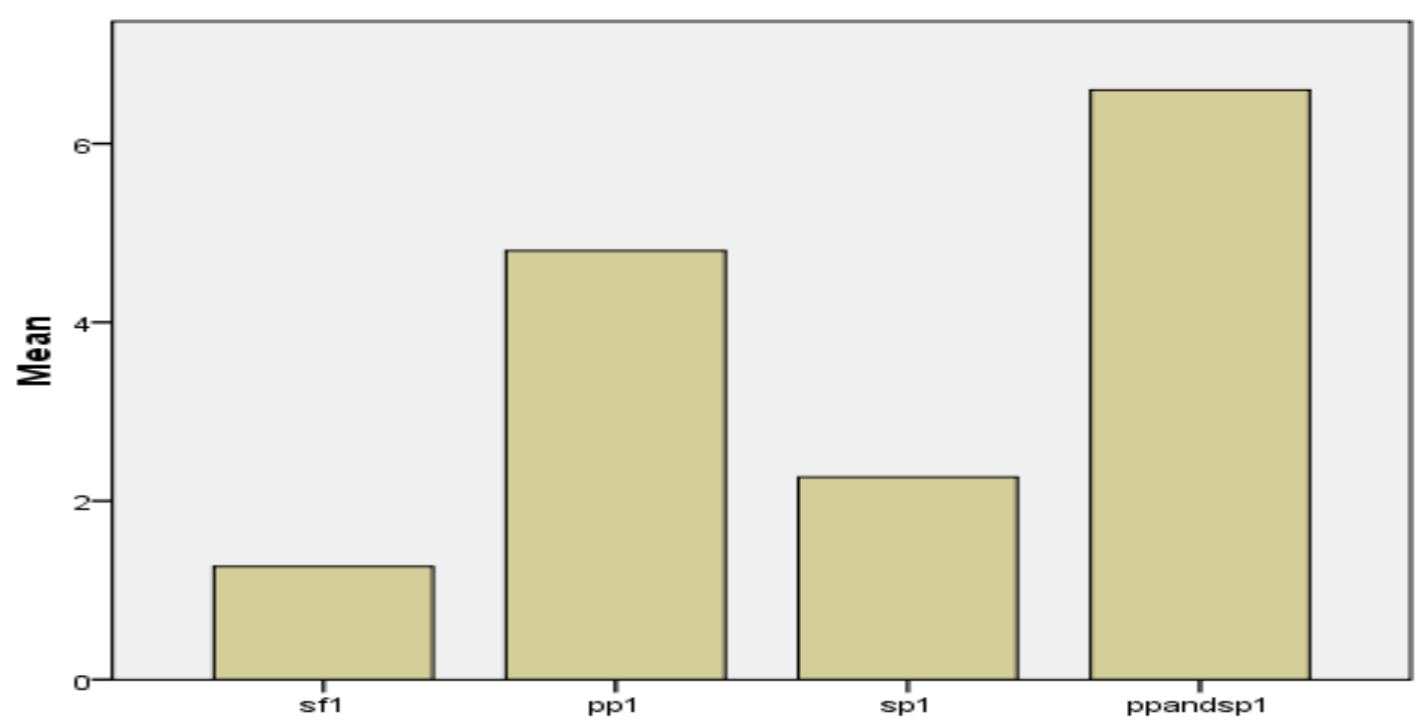

$\mathrm{Sf}=$ simple future $\quad \mathrm{pp}=$ present perfect $\quad \mathrm{sp}=$ simple present $\quad \mathrm{pp} \& \mathrm{sp}=$ present perfect and simple present

As it is observed from Levene's Test of Error Variances (Table 3), the significance level for present perfect and simple present option was greater than .05. This means that participants' answers to comprehension test were homogenous.

Table 3: Distribution of answers regarding tenses in comprehension test

\begin{tabular}{lllll}
\hline \multicolumn{5}{l}{ Levene's Test of Equality of Error Variances $^{\mathrm{a}}$} \\
\hline & $\mathrm{F}$ & $\mathrm{df}_{1}$ & $\mathrm{df}_{2}$ & Sig. \\
\hline sf1 & 2.117 & 1 & 13 & .169 \\
pp1 & .975 & 1 & 13 & .342 \\
sp1 & 6.930 & 1 & 13 & .021 \\
Pp \& sp1 & 4.263 & 1 & 13 & .060 \\
\hline
\end{tabular}

\section{Production test}

According to Figure 2, majority of participants in intermediate proficiency level chose present perfect as the best translation equivalent for FPPT. However, the advanced group selected FPPT correctly.

Figure 2: Distribution of answers regarding tenses in production test 


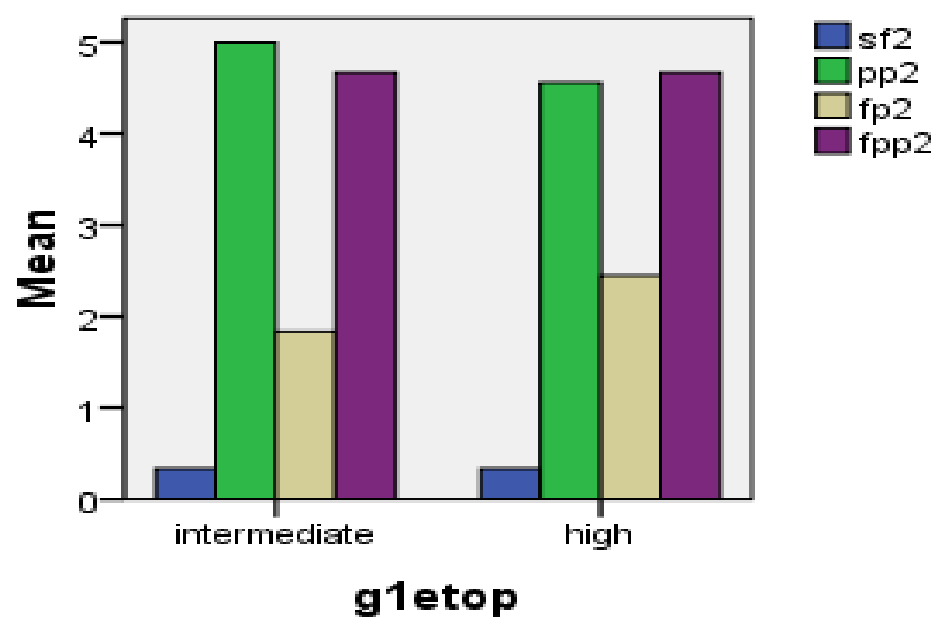

As it can be observed from Table 2, the significance level for production test was greater than .05 regarding all tenses, so, it can be inferred that participants' answers to production test were not homogenous.

Table 4: Distribution of answers regarding tenses in production test

\begin{tabular}{lcccc}
\hline \multicolumn{5}{l}{ Levene's Test of Equality of Error Variances } \\
\hline & $\mathrm{F}$ & $\mathrm{df}_{1}$ & $\mathrm{df}_{2}$ & Sig. \\
\hline sf2 & 1.560 & 1 & 13 & .234 \\
pp2 & 3.013 & 1 & 13 & .106 \\
fp2 & 9.796 & 1 & 13 & .008 \\
fpp2 & .367 & 1 & 13 & .555 \\
\hline
\end{tabular}

\section{Discussion and Conclusion}

The language properties inherent in the human mind constitute 'Universal Grammar', which consists of a set of general principles that apply to all grammars and a set of parameters that vary across different languages. Therefore, to acquire language, the child needs UG along with evidence about a particular language; in other words, he needs to hear sentences of English to know how to set the parameter for Verb, Subject, and Object order. The evidence he encounters can be positive or negative. Positive evidence are actual sentences of a language. By contrast, negative evidence are two kinds, including direct and indirect. Direct negative evidence means the corrections of the child's mistakes by adults. Indirect negative evidence pertains to nonoccurrence of something in the language the child hears. Accordingly, positive evidence and, 
to some extent, indirect evidence lead to L1s acquiring; whereas, direct evidence or correction have no role in L1 acquisition.

Various scholars present different hypotheses about availability of universal grammar in second language acquisition process. Four different models proposed in this field were discussed briefly in this study; then, one of these recent hypotheses pertaining to partial access to UG, i.e. Interpretability Hypothesis (Hawkins and Hattori, 2006; Tsimpli and Dimitrakopoulou, 2007; Tsimpli and Mastropavlou, 2007) was examined by evaluating acquisition of future perfect progressive tense by Persian L2 learners of English.

To this end, the syntactic structures of future perfect progressive tense were compared in both English and Persian. The three hypotheses made earlier are discussed in the following.

Hypothesis one: Regarding the results gained in previous sections, predictions with respect to interpretability hypothesis are confirmed. The homogeneity of participants' answers according to Levene's Test of Error Variances shows that Persian L2 learners of English have few problems in comprehending a feature logically interpretable in their L1. In contrast to comprehension test, participants' answers to production test were heterogeneous. However, participants with advanced English proficiency level selected the right options in production test. In a nutshell, according to principles of interpretability hypothesis, Persian L2 learners of English have no problem in acquiring future perfect progressive tense which is logically interpretable but phonologically uninterpretable in their L1.

Hypothesis two: Based on the interface hypothesis, Persian L2 learners were supposed to eliminate uninterpretable features while producing or translating FPP English sentences to Persian. However, findings revealed that participants in both groups did not eliminate the syntactic features of FPPT, but substituted them with other phonologically interpretable features.

Hypothesis three: Yarmohammadi suggested that simple future tense is a compensatory tense for FPPT (Yarmohammadi, 2005). However, as it can be observed from Table 3, this tense has the lowest mean score $(M=1.27)$ among other options since simple future changes the meaning of sentence. According to findings, simple present and present perfect were the most frequent tenses used as compensatory tenses for rendering FPPT in Persian. Regarding the fact that future perfect progressive tense is a structure with low frequency of occurrence in English, it implies that inclusion of FPPT is not necessary in intermediate courses. On the other hand, because of its infrequency in texts, advanced learners of English have little opportunity to improve their knowledge on this tense. Thus, enough care should be paid by teachers to explain this structure properly so that learners can internalize it well.

\section{References}


Al-Thubaiti, K. (2007). Age effects on the acquisition of uninterpretable features by proficient Saudi Arabic speakers of English. In the proceedings of the 5 th University of Cambridge Postgraduate Conferences in Language Research.

Bley-Vroman, R. (1989). The logical problem of second language learning. In S. Gass and J.

Bond, K., Gabriele, A., Fiorentino, R., \& Aleman Banon, J. (2011). Individual differences and the role of the L1 in L2 processing: An ERP investigation. In Proceedings of the 11th Generative Approaches to Second Language Acquisition Conference (GASLA 2011) (pp. 17-29).

Clahsen, H., \& Muysken, P. (1986). The availability of universal grammar to adult and child learners-a study of the acquisition of German word order. Interlanguage studies bulletin (Utrecht), 2(2), 93-119.

Cook, V. (1985) Chomsky’s Universal Grammar and second language learning. Applied Linguistics. 6/1. 1-18.

Arche, M. J., \& Domínguez, L. (2008). Optionality in L2 grammars: the acquisition of SV/VS contrast in Spanish.Ellis, R. (1994). The study of second language acquisition. Oxford: Oxford University Press.

Fallahi, M. (1991). Contrastive linguistics and analysis of errors, Iran University Press.

Flynn, S. (1987). A parameter-setting model of L2 acquisition. Dordrecht: Reidel.

Hawkins, R., \& Hattori, H. (2006). Interpretation of English multiple wh-questions by Japanese speakers: A missing uninterpretable feature account. Second Language Research, 22(3), 269-301.

Hodgson, M. (2009). The Interaction between Lexical-Semantics and Morphosyntax: A Study on the Development of Verbal Forms in L1 and L2 Spanish. 3rd Conference on Generative Approaches to Language Acquisition North America (GALANA 2008), Citeseer.

Kong, S. (2005). The partial access of Universal Grammar in Second Language Acquisition: an investigation of the acquisition of English Subjects by L1 Chinese speakers. Journal of East Asian Linguistics, 14(3), 227-265.

Mirhassani, A. (1989). Contrastive analysis of English and Persian verbs. IRAL 27(4), 325-346.

Montrul, S., Foote, R., Perpiñán, S., Thornhill, D., \& Vidal, S. (2006). Full access and age effects in adult bilingualism: An investigation of Spanish accusative clitics and word order. In Selected papers from the 9th Hispanic Linguistics Symposium. Sommerville, MA: Cascadilla Proceedings Project.

Otsu, Y., \& Naoi, K. (1986). Structure-dependence in L2 Acquisition in L. White, (1989). Universal Grammar and Second Language Acquisition.

Prévost, P., \& White, L. (2000). Missing surface inflection or impairment in second language acquisition? Evidence from tense and agreement. Second language research, 16(2), 103-133.

Quirk, R., \& Greenbaum, S. (1973). A concise grammar of contemporary English. Harcourt School.

Ritchie, W. (1978). The right roof constraint in an adult-acquired language. Second language acquisition research: Issues and implications, 33-63.

Rothman, J., Iverson, M., \& Judy, T. (2009). Bound variable, split antecedent and ellipsis interpretations in L2 Portuguese: implications for L2 acquisition theories (Variável ligada, antecedente cindido e interpretações de elipse em Português como L2: implicações para as teorias de aquisição de L2). Estudos da Língua (gem), 7(2), 261.

Rothman, J., Judy, T., Guijarro-Fuentes, P., \& Pires, A. (2010). On the (Un)-Ambiguity of Adjectival Modification in Spanish Determiner Phrases: Informing Debates on the Mental Representations of L2 Syntax. Studies in Second Language Acquisition, 32(1), 47-77. 
Schachter, J. (1988). Second language acquisition and its relation to Universal Grammar. Applied Linguistics, 9(3), 219-235.

Gass, S. M., \& Schachter, J. (Eds.). (1989). Linguistic perspectives on second language acquisition. Cambridge University Press. Schachter (ed.) Linguistic prespectives on second language acquisition. Cambridge: Cambridge University Press.

Tanner, D. (2008). Agreeing that agreement isn't the problem. In Selected Proceedings of the 2007 Second Language Research Forum. Somerville, MA: Cascadilla Proceedings Project (pp. 22-34).

Towell, R., \& Hawkins, R. D. (1994). Approaches to second language acquisition. Multilingual matters.

Tsimpli, I. M., \& Dimitrakopoulou, M. (2007). The interpretability hypothesis: Evidence from wh-interrogatives in second language acquisition. Second Language Research, 23(2), 215-242.

Tsimpli, I. M., \& Mastropavlou, M. (2007). Feature interpretability in L2 acquisition and SLI: Greek clitics and determiners. The role of formal features in second language acquisition, 143-183.

White, L. (1986). Implications of parametric variation for adult second language acquisition: an investigation of the pro-drop parameter. Experimental approaches to second language acquisition, 55, 72.

Yarmohammadi, L. (2005). A contrastive phonological analysis of English and Persian, Shiraz: Shiraz University Press. 